120

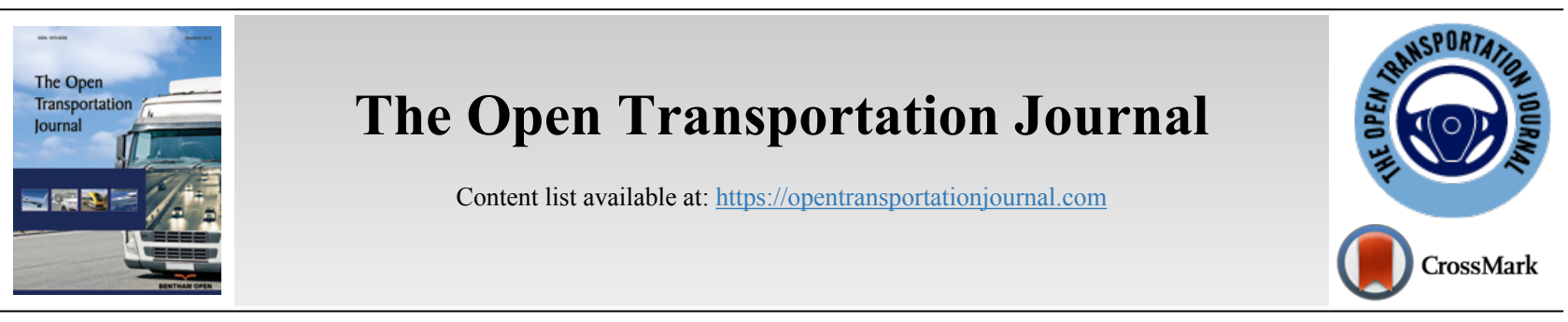

CASE REPORT

\title{
A Comparison of Traffic Flow Performance of Roundabouts and Signalized Intersections: A Case Study in Nigde
}

\author{
Hatice G. Demir ${ }^{1, *}$ and Yusuf K. Demir ${ }^{1}$ \\ ${ }^{I}$ Department of Civil Engineering, Faculty of Engineering, Niğde Ömer Halisdemir University (NOHU), Nigde, Turkey
}

\begin{abstract}
:
Background:

Intersections affect the safety and capacity of urban traffic. Therefore, the design and selection of the type of intersection need to be made very carefully. According to the demand level, a different intersection can be designed. Signalized intersections are one of the intersection types in which the sequence and duration of the flow at the intersection are provided by the lights. Generally, this type of intersection is used on roads with high traffic volume. Modern roundabouts are one of the types of circular intersections that provide advantages over other types of intersection in terms of smooth operation and safety. Modern roundabouts exist in several types today worldwide. In practice, the distinction about the kinds of roundabouts would not be fully clarified; as a result, queuing and delay can be seen as negative effects.
\end{abstract}

Methods:

In this study, to make a distinction and clarify the kinds of roundabouts, first, the roundabouts types are introduced according to geometric and operational aspects. A signalized intersection, where a circular island is placed and also signalized, was investigated in terms of capacity, delay, and emissions located in Niğde. The traffic flow performance of the current state (nested signalized roundabout) was calculated with HCM Method (for signalized intersection) using SIDRA and compared with roundabout solutions of the intersection with HCM6 (for roundabout) method using SIDRA Intersection analysis software.

Results:

From the results of the intersection capacity analysis study based on HCM6, it was seen that the application of a roundabout scenario (intersection considered as a modern roundabout) showed higher performance at the intersections than the intersection having a secondary signal. Capacity increased to $67.8 \%$, the average delay decreased to $72.8 \%$ and 95 th percentile queue dropped to $82.2 \%$.

Conclusion:

Roundabout controlling instead of a nested signal system can be an example of the increase in the performance of traffic flow. This highlights the importance of choosing the appropriate roundabout design.

Keywords: Nested signalized intersection, Roundabouts, Capacity, Delay, HCM, SIDRA

\section{INTRODUCTION}

Signalized intersections are the type of intersection in which the sequence and duration of flows at the intersection are provided by the lights. Generally, this type of intersection is used on roads with high traffic volume. Accurate calculation of signaling in urban traffic will also greatly affect traffic patterns at intersections. The signalized intersection is designed to regulate traffic (minimize disturbances, discipline), reduce

* Address correspondence to the author at the Department of Civil Engineering, Faculty of Engineering, Niğde Ömer Halisdemir University (NOHU), Nigde, Turkey; Tel: 05353954549; E-mail: hgocmen@gmail.com accidents, minimize vehicle delays, and optimize road capacity (clustering vehicles and minimizing time losses) and calming traffic. The increase in the number of intersections with the control signal system in the central island is remarkable in recent years in Turkey. Sometimes these intersections are also described as signalized roundabouts (Fig. 1).

Modern roundabouts are shown as an alternative to signalized intersections due to the many benefits that they provide $[1,2]$. A study discussed the reasons for recommending modern roundabout under their titles safety improvements, operation improvements, community livability, 
traffic calming, aesthetic gateway treatments, etc. Modern roundabouts exist worldwide in several types today.

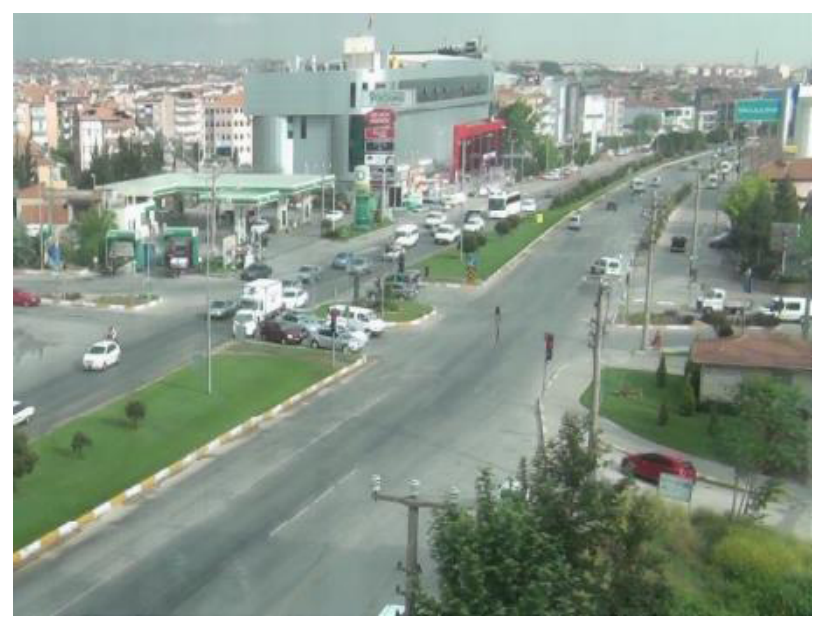

Fig. (1). Example of a signalized roundabout with insufficient storage space [6].

It is seen that some countries have their roundabout guides, and they have made their geometry designs accordingly. Design of roundabouts from the United Kingdom, French Guides SETRA for large roundabouts and SETUR for urban cases, VSS Swiss Roundabout Guide [1], Roundabout Guidelines from German Association FGSV [3], USA guidelines [4], Polish Guidelines, Austrian Guidelines, and Croatian Roundabout Design Guidelines on State Roads [5] are some of these. Currently, in Turkey, there are no design guidelines for modern roundabouts and it is in contrast to many countries.

The choice of intersection design is very important. Fig. (2) shows a well-known graph of intersection type which is based on traffic demand at main road and circulation road. The wrong arrangement and the choice of the type of intersection can bring many negative effects such as environmental pol- lution caused by traffic accidents, delays, queuing, stop and go condition and cost. For example, if the storage area in the central island of signalized intersection is insufficient, the corresponding lanes may be blocked by left-turning flow vehicles, thereby affecting the overall performance of the intersection. This could also be seen where secondary traffic control signals are installed on the circulation island of a roundabout for controlling left-turning movements. This type of controlled roundabout is defined in this study as a nested signalized roundabout.

In this study, to make a distinction and clarify the kinds of roundabouts, first, the roundabouts types are introduced according to geometric and operational aspects in a detailed manner. Then, a nested signalized intersection located in Niğde is studied in terms of traffic flow performance. The intersection (Fig. 3) includes two signaling controls. The primary signal controls the main approach movements while a secondary signal (nested) controls left turning and U-turn movements. The calculation procedure for traffic flow performance of nested type roundabout is carried out with HCM methods using SIDRA.

\section{ROUNDABOUTS}

A traffic circle is a circular intersection that provides a circular traffic pattern with a significant reduction in the crossing conflict points. Rotaries, neighborhood traffic circles, signalized traffic circles and roundabouts are four common types of circular intersection. Rotaries are the name given to circular intersections used before the 1960s. It is noticeable that the diameters of these intersections are very wide (over 100 meters). Therefore, there is a high travel speed of the circulatory roadway (over $50 \mathrm{~km} / \mathrm{h}$ ). There is little or no horizontal deflection of the roadway of through-traffic and traffic operation is valid according to the "yield to the right" rule (NCHRP, 2010). Columbus Circle in New York City, Arc de Triomphe in Paris and Dupont Circle in Washington, D.C., are three examples of older-style traffic circles.

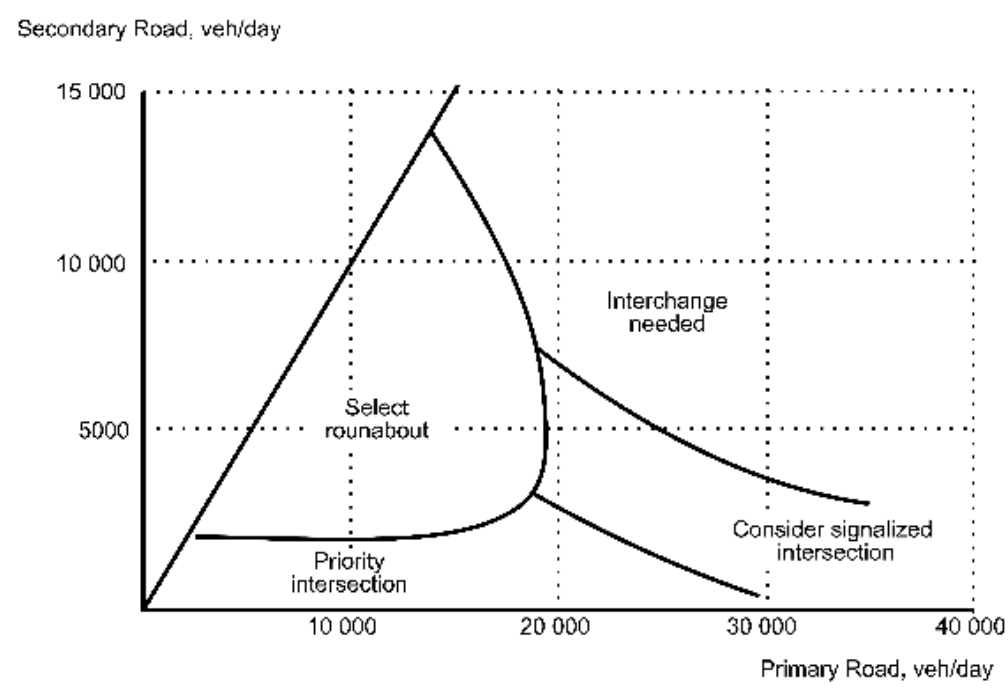

Fig. (2). Representation of intersection types according to traffic demand [7]. 


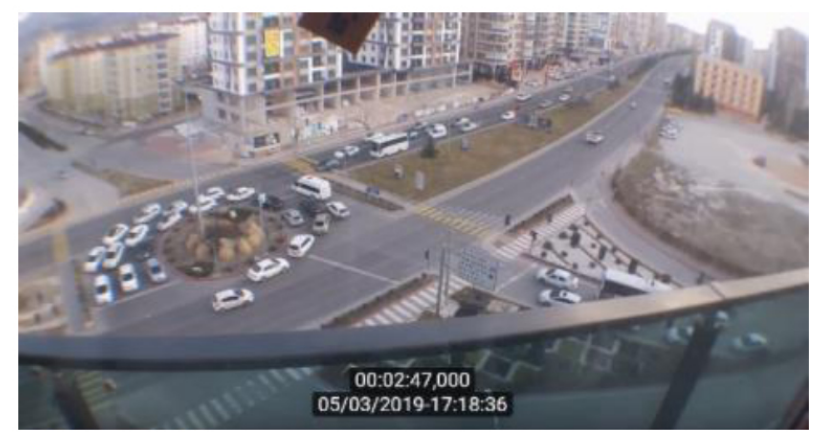

Fig. (3). Working Area (intersection with a nested signal controlling in Niğde).

Neighborhood traffic circles have diameters that are much smaller than rotaries and therefore allow much lower speeds $[8$, 9]. Neighborhood traffic circles are raised island built at the intersections of the local streets for calming traffic so that drivers need to reduce their speed to move comfortably. The outer circle can be adjusted to fit large vehicles, while the inner circle can be landscaped for aesthetic appearance. The intersection approaches may be uncontrolled or stop-controlled. They do not typically include raised channelization to guide the approaching driver to the circulatory roadway. At some traffic circles, when left turns are allowed to the left of the central island (clockwise around), conflicting points may occur with other circulating traffic $[4,10]$.

Signalized traffic circles are old-style circular intersections where traffic signals are used to control one or more entry circulating points [4]. Due to the increase in traffic, these traffic circles and town squares are nowadays mostly controlled by traffic signals (they are mainly located within city centers where traffic is high) so that potential traffic accidents can also be prevented. Traffic signals have been operated at peak periods of traffic since the first installation and this situation continues today [11].

A roundabout is a form of circular intersection in which traffic travels counterclockwise (in the United States and other right-hand traffic countries) around a central island and where the entering traffic must yield to the circulating traffic [4]. In Fig. (4), the main design elements of roundabouts are shown. The central island provides a visual barrier across the intersection to the driver entering there [12] whereas the raised splitter islands at each approach separate the entry and exit lanes of a street. These splitter islands are designed to deflect traffic, reduce vehicle speed [13] and provide pedestrian refuge.

Engineers use a variety of design techniques, mostly geometric, to slow vehicles as they approach, circulate, and exit a roundabout [13]. As a result, they reduce the conflict points, reduce the high speed, improve traffic safety, reduce delays and increase the capacity. The slower circulating speed at roundabouts allows entering vehicles to move with smaller gaps in the circulating traffic flow, making more gaps available, and increasing the volume of traffic to pass [15].

Studies by the Federal Highway Administration have found that roundabouts can increase the traffic capacity by 30 percent to 50 percent compared to traditional intersections [16]. Reducing stopping and queuing patterns can also add to environmental benefits. Studies have shown a reduction in greenhouse gas emissions from a range of 17 to 65 percent and fuel consumption by 28 percent while also reducing vehiclerelated fatalities by 90 percent, injuries by 75 percent and all crashes by 35 percent when a signalized intersection was replaced by a roundabout $[17,18]$. At rotaries, vehicles need larger gaps in the circulating traffic flow, reducing the volume of the traffic processed [19].

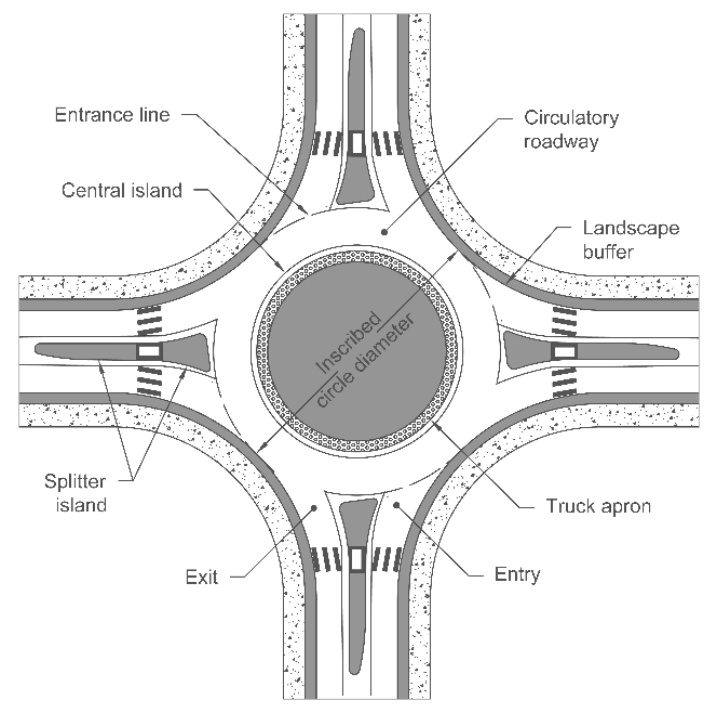

Fig. (4). Main design elements of roundabouts [14]. 
Numerous models for determining roundabout capacity under mixed-traffic conditions suggest that it is strongly affected by geometric elements [5, 20]. Most importantly, geometric elements influencing operational efficiency (i.e. entry capacity) are entry width, entry radius, flare length, diameter of the entry angle inscribed circle and number of entry lanes [5]. Based on the comparison of guidelines, it has been found that all European guidelines are similar in terms of main geometry design elements except the UK (the geometry parameters of the UK are slightly different). The USA guidelines have bigger values of geometry design when compared to European guidelines. This is because of longer design vehicles and dimensions related to specific national conditions and drivers' behavior [5]. The comparison of the roundabout category, according to German and USA Guide- lines $[5,8]$. is shown in Table $\mathbf{1}$.

In Fig. (5), there is another demonstration of different roundabout types that could be seen according to their size (measured by inscribed circle diameter) and range of demand (measured by the ADT of the whole intersection) determined by German guidelines. It could be seen that the policy of intersection is made according to the sufficient capacity.

The first mini-roundabout on the public road network was put into operation in Peterborough (Great Britain) in 1968 and has been used thousands of times since then [21]. As can be seen in the chart in Fig. (5), mini-roundabouts are the intersections with low inscribed circle diameter and low capacity. They are generally used in urban areas with less operating speed. The central island can be traversed by large vehicles, as shown in Fig. (6).

Table 1. The comparison of roundabout category according to German and USA Guidelines.

\begin{tabular}{|c|c|c|c|c|c|c|}
\hline- & Roundabout Type & - & - & - & - & - \\
\hline Design Element & Mini & - & Single-Lane & - & Multi-Lane & - \\
\hline- & Germany & USA & Germany & USA & Germany & USA \\
\hline Desirable Maximum Entry Speed $(\mathrm{km} / \mathrm{h})$ & $25-30$ & $25-30$ & $30-40$ & $30-40$ & $50-60$ & $40-50$ \\
\hline Maximum number of entering lanes per approach & 1 & 1 & 1 & 1 & 32 & 32 \\
\hline Typical inscribed circle diameter & $13-22$ & $25-30$ & $30-40$ & $30-40$ & $50-60$ & $40-50$ \\
\hline Central Island treatment & Traversable & Traversable & Raised & raised & raised & Raised \\
\hline- & up to approximately (veh/day) & - & - & - & - & - \\
\hline $\begin{array}{l}\text { Typical daily service volume on 4-leg roundabout } \\
\text { (veh/day)* }\end{array}$ & 12,000 & 15,000 & 25,000 & 25,000 & 32,000 & 45,000 \\
\hline- & - & - & - & - & - & for two- lane \\
\hline
\end{tabular}

*Operational analysis needed to verify upper limit for specific applications

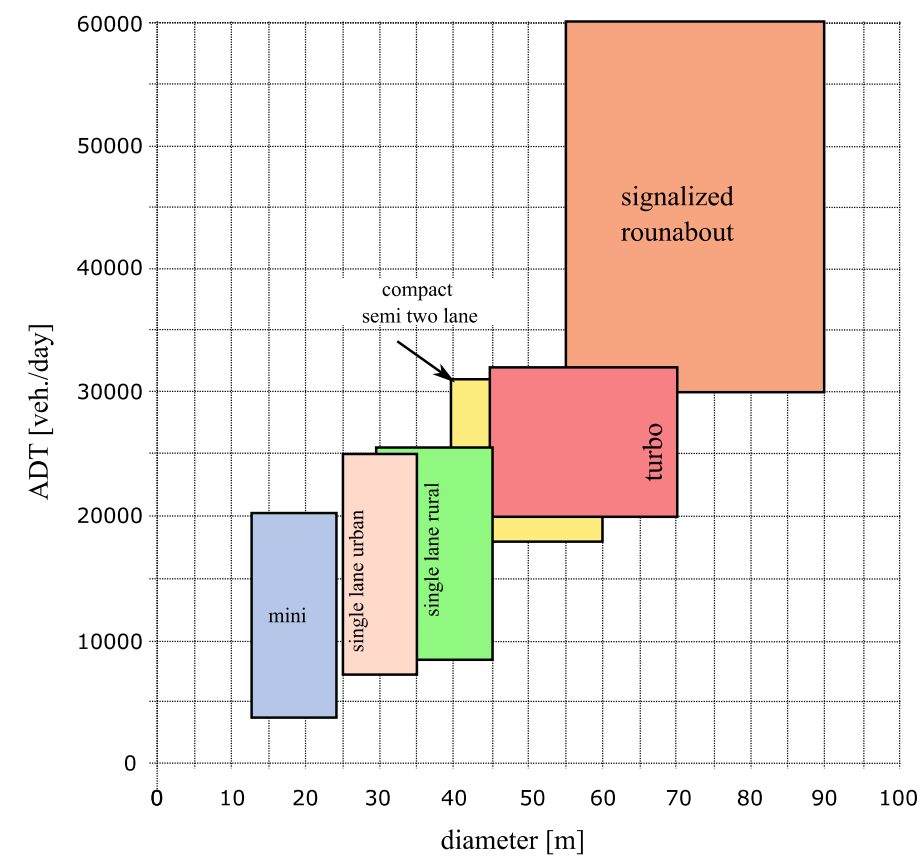

Fig. (5). Definition of types of roundabouts by their inscribed circle diameter and their potential range of applicability in terms of average daily traffic (ADT) [22]. 


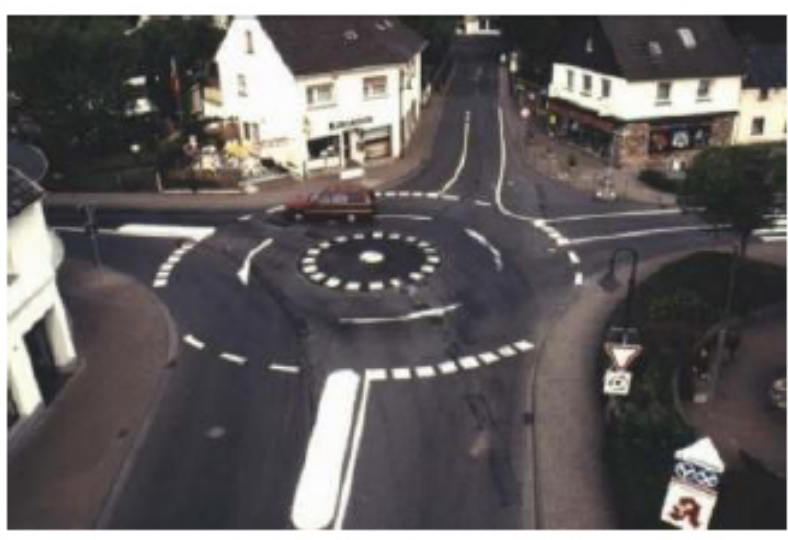

Fig. (6). An example of Mini roundabout in Kall [22].

Single-lane roundabouts are used in urban and rural areas and defined as having single lane entry at all legs and one circulating lane [23]. The difference from mini-roundabouts is that they have larger inscribed circle diameters, non-traversable central islands, and their design allows higher speeds on entries, circulating lane, and exits [24]. Rural roundabouts may have larger diameters than urban roundabouts to allow slightly higher speeds at the entries, on the circulatory roadway and on the exits [23]. In Germany, the single lane roundabout is still the reference type to which all other types are compared [3].

In the German terminology, there is still an intermediate type of roundabout which could be called - loosely translated compact semi two lane roundabout. Roundabouts of this type have a diameter between 40 and 60 meters and a circulating lane 8 and 10 meters wide without the lane marking on the circle. Besides these measures, they are very much designed like a single lane roundabout and in the US, they are treated like single lane [3].

Multilane roundabouts include all roundabouts that have at least one entry with two or more lanes. In some cases, the roundabout may have a different number of lanes on one or more approaches. For example, a roundabout with both twolane entries and single-lane entries would still be considered a multilane roundabout. They also include roundabouts with entries on one or more approaches that are from one to two or more lanes. These need wider circulatory roadways to accommodate more than one vehicle travelling side-by-side. The speed at the entry, on the circulatory roadway, and at the exit is similar or may be slightly higher than those for the single-lane roundabout [24]. Multi-lane roundabouts have more problems than single-lane roundabouts. Drivers might not be able to enter the appropriate lane, leading them to change lanes within the circulating lane [25]. Due to a possibility of path overlaps at the entry and the exit as well as higher speeds, these types of roundabouts are less safe in comparison with mini and single-lane roundabouts [5]. There are tradeoffs between safety and operational performance in this type of roundabouts [25]. The geometric design includes raised splitter islands, truck apron (if required), a non-traversable central island, and appropriate entry path deflection [24].

Turbo roundabouts are multi lanes roundabouts with spiral road markings and separated circulating lanes. They have much greater capacity and have more safety than standard multi-lane roundabouts, while they do not need any additional space [26].

A signalized roundabout is an intersection type constructed by placing traffic signals in multilane roundabouts that control the traffic [26] as shown in Fig. (7). Signalized roundabouts originate from the UK and date back to the early seventies of the previous century; but from the year 1991, signalization became a popular method of traffic control in roundabouts. Signalized roundabouts are well-known in Belgium, the Netherlands, Denmark, Sweden and Germany [11]. It can be seen from Fig. (5) and Table 1 that the signalized roundabout capacity is over 32000 vehicles per day and the inscribed circle diameter is beyond 50 meters.

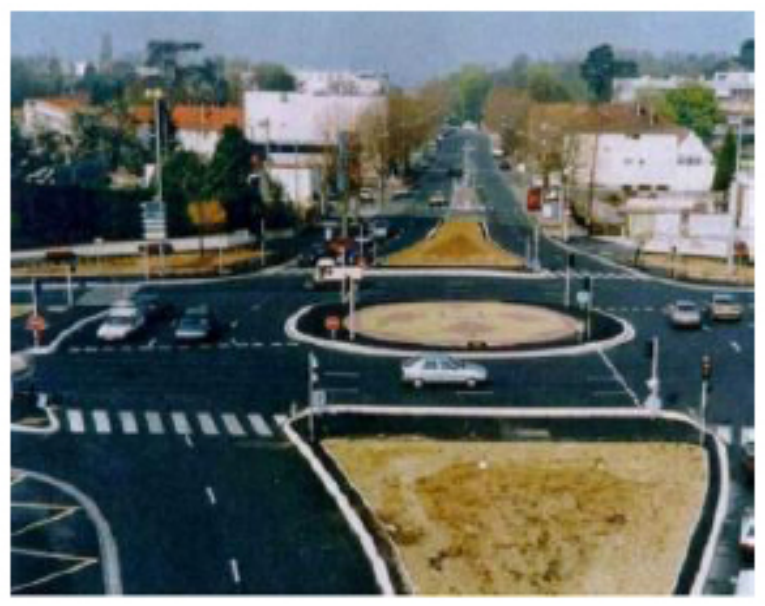

Fig. (7). Signalized roundabouts in France [28].

Traffic signals are generally added to a roundabout to solve specific problems, mainly related to capacity or quality of traffic flow. Insufficient capacity of the roundabout, heavy leftturning traffic flow, and unacceptable delays and/or queues on one or more of the connecting legs are the most important of them. Sometimes the problems to solve are also traffic safetyrelated. Such as drivers experience difficulties when merging with the traffic on the multilane roundabout due to high circulating speeds and for pedestrians and cyclists it is difficult to cross multilane legs of the roundabout [26]. There are no standard design parameters for signalized roundabouts. The designs of existing signalized roundabouts are mostly based on general road-design experience. In general, the design should be based on the fact that drivers should be able to reach their desired destination in relatively safe circumstances [26]. It can be seen that the two main signal controls of roundabouts are: direct control and indirect control. Direct control rules both external and internal links in a roundabout while indirect control rules only the inflows to the round-about. The roundabout can either get full or partial signal control and signals can either be used permanently or for part-time [27]. According to the FHWA guide, a primary requirement for fully signalized roundabouts is the capacity to gather vehicles that are not moving in the circulatory roadway without creating queues that spill back to block upstream exits or entries. Unsignalized roundabouts that are built with diameters and roadway widths could not be fully signalized without increasing the diameter lane width, and/or additional lanes [28]. 


\section{TEST SITE}

Working area is shown in Fig. (1); it is a fixed-time, 3phase signal controlled, 4-leg, and the 40-meters-wide intersection with $70 \mathrm{~km} / \mathrm{h}$ speed limits on major roads. The major road has 3 lanes in each direction. In the middle of the intersection, there is a 16 meters central island and the width of the circulating area is about 3 lanes. The intersection and the central island are signalized controlled. It can be seen that this situation causes vehicle accumulation (queuing) and delay due to the lack of space for vehicles around the rotating island as shown in Fig. (3).

The traffic volume values were obtained from the traffic counts on March 5th, 2018 between 16: 20-17: 20, which is the peak hour of the evening. The volume counts periods on each approach were 60 minutes. Also, left-turning, right-turning, and through-movement traffic volumes in the approaches were classified according to vehicle types and converted into a passenger car unit (pcu) in Fig. (8).

\section{METHODS}

Although signalized roundabouts have been widely used in recent years, the design criteria are not clear and the performance of these types of intersections can only be measured by simulation programs [29]. Çakıcı and Murat [29] proposed an approach for the calculation of signal cycle time and phase plan at signalized roundabouts. The effectiveness of the design was evaluated by considering different types of intersection phase plans and measured by considering the delay performance criterion. As a result of the analysis, as the left turn ratio increased, it was found that different alternatives should be preferred instead of roundabouts, depending on the increase in the number of phases [30].

In this study, capacity and delay determine the traffic flow performance of the current state (nested signalized roundabout), which are calculated with the HCM Method (for signalized intersection) using SIDRA. As a new approach, the green interval of the secondary signal is added as a left-turn phase to the primary phase plan. Each lane group capacity is a function of effective green time in seconds $(\mathrm{g})$, cycle time (C) in seconds, saturation flow (s) of vehicles per hour per lane, and the number of lanes $(\mathrm{N})$.

$$
\mathrm{c}=\mathrm{N} \times \mathrm{s} \times \frac{\mathrm{g}}{\mathrm{C}}
$$

The cycle time for capacity analysis is,

$$
\mathrm{C}=\mathrm{Cp}+\mathrm{g}_{\mathrm{s}}
$$

Where $\mathrm{C}$ is the cycle time (seconds) of the combined signal control, $\mathrm{C}_{\mathrm{p}}$ is the primary cycle time and $\mathrm{g}_{\mathrm{s}}$ is the green time for left turning and u-turning movements with a secondary signal. In the signalized intersections, capacity analysis with HCM is out of the scope of this study, so no calculation details have been entered. You can refer to the study mentioned as reference [31] for detailed accounts.

Weaving theory was used to describe the traffic characteristics of traffic circles such as Clayton Methods, Wardrop's method etc, at the Department of Environment in the UK. The transport and road research laboratory (U.K.) which has pioneered research on this aspect, recommends the follo-wing formula which is a modification of the well-known Wardrop formula [32]:

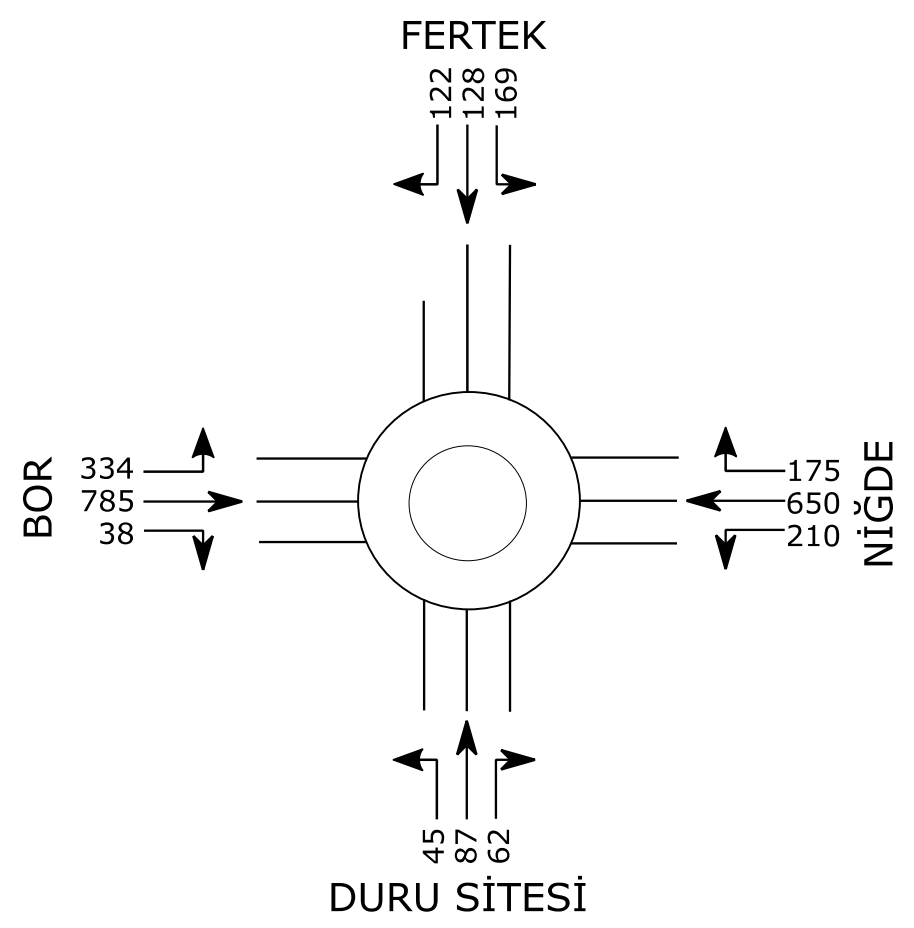

Fig. (8). Turning flows rate $\left(\mathrm{pcuh}^{-1}\right)$ at the intersections. 


$$
\begin{gathered}
Q_{p}=\frac{280 w\left(1+\frac{e}{w}\right)\left(1-\frac{P}{3}\right)}{1+\frac{w}{l}} \\
P=\frac{b+c}{a+b+c+d}
\end{gathered}
$$

$Q_{\mathrm{p}}$ is the practical capacity ( $\left.\mathrm{pcu} / \mathrm{h}\right) ; w$ is the width of weaving section $(m)$, e is the average entry width $(m), l$ is the length of weaving section $(m)$ and $P$ is the proportion of weaving traffic. $P$ is calculated by the ratio of the sum of crossing streams ( $b$ and $c$ ) to the total traffic on the weaving section. Long weaving distance for merging entries causes circles to be large. In modern roundabouts, no weaving distances are necessary. Circulating traffic always keeps moving.

The capacity of modern roundabouts is principally a function of the availability of entering vehicles to accept gaps in the conflicting circulating traffic stream. Because roundabouts (typically) do not have traffic signals installed, the capacity emerges from the geometric characteristics of the roundabout itself, and the behavioral characteristics of the drivers [31].

The capacity estimation method of roundabouts can be classified as the empirical regression analysis method and analytical method. The former model is based on a regression model estimating the relationships between entering volume and circulating volume as the dependent variable and independent variable, respectively [33]. It requires a large number of roundabouts with a full range of traffic volumes for estimation and calibration of parameters [34]. This approach emphasizes the effect of geometrics such as entry number of lanes and width, circulating lanes, and width and is independent of driver behavior characteristic underlying British Roundabout Methodology [31]. The regression method, to calculate roundabout capacity, needs a large number of data survey especially under the condition of saturated traffic flow.

The British roundabout capacity equation was developed by the Transport Research Laboratory (TRL). The FHWA2000 Roundabouts, an informational guide, provides the capacity equation (5) where $Q_{e}$ is the entry capacity (Fig. 9), $Q_{c}$ is conflicting flow [35] simplifying TRL model by assuming a particular geometric design even though the equation is presented as applicable for inscribed diameters from 24 to 55 meters.

$$
Q_{e}=1212-0.5447 Q_{c}
$$

However, equation (5) is limited so that the combined entry and circulating flow cannot exceed 1,800 vehicles per hour. This occurs when the circulating flow is about 1,291 vehicles per hour. At higher flow rates, the entry capacity is the difference between 1,800 vehicles per hour and the circulating flow.

The analytical capacity estimation methods of roundabouts are based on gap-acceptance theory, which is concerned with the dynamic characteristics and priority rules, while critical gap and follow up headway are its key parameters [36] and linked to the empirical observation of drivers' behavior. The critical gap represents an indifference point in which drivers accept or reject to enter circulation traffic. Follow-up headway is the additional time beyond the critical gap needed for each additional vehicle to enter the conflicting traffic stream [31]. The well-known behavioral roundabout capacity models that depend on the gap acceptance theory are Tanner's [37 - 39].

$$
Q_{e}=\frac{3600 \cdot q_{c} \cdot\left(1-\Delta \cdot q_{c}\right) \cdot e^{[-q c(T-\Delta)]}}{1-\exp ^{\left(-q c \cdot T_{o}\right)}}
$$

$\mathrm{Q}_{e}$ is the entry capacity $(\mathrm{veh} / \mathrm{h}), \mathrm{q}_{\mathrm{c}}$ is the circulating flow in front of the entry approach (veh/h), $\Delta$ is the minimum headway between the circulating vehicles (s), $\mathrm{T}$ is the critical gap (s) and $\mathrm{T}_{\mathrm{o}}$ is the follow-up time (s).

The Highway Capacity Manual 2000 HCM 2000 provides the following equation for determining the approach capacity for a single-lane roundabout.

$$
c_{a}=\frac{V_{c} e^{-V_{c} t_{c} / 3600}}{1-e^{-v_{c} t_{f} / 3600}}
$$

Where, $c_{a}$ is the approach capacity $(\mathrm{veh} / \mathrm{h}), \mathrm{V}_{\mathrm{c}}$ is the conflicting circulating traffic $(\mathrm{veh} / \mathrm{h}), \mathrm{t}_{\mathrm{c}}$ is the critical gap (s), and $t_{\mathrm{f}}$ is the follow-up time (s).

The roundabout capacity model presented in the 2010 edition of the Highway Capacity Manual HCM 2010 [1] was developed as an exponential regression model to observe data at 31 sites in the US with parameter estimates based on gap acceptance theory. The accuracy of capacity calculations at roundabouts is dependent largely on the accurate estimation of the critical gap and follow-up headway [40].

HCM2010, the fifth edition, developed new methodologies for evaluating roundabout performance. In HCM2010, multilane roundabouts with up to two entry lanes and one bypass lane per approach were considered in capacity estimates [41] different from the HCM2000 edition.

The model HCM6 used to calculate capacity at roundabouts is a semi-analytical model. The model is a mixture of regression and the gap-acceptance model. The model calculates the capacity at the entry points entering the roundabout using the critical gap and follow-up time obtained as a result of observations of roundabouts in the United States. HCM 2010 and HCM6 use the same model for capacity calculation. Unlike HCM6, in HCM 2010, model parameters critical gap $\left(t_{c}\right)$ and follow-up time $\left(\mathrm{t}_{\mathrm{f}}\right)$ have been updated with new data [42]. 


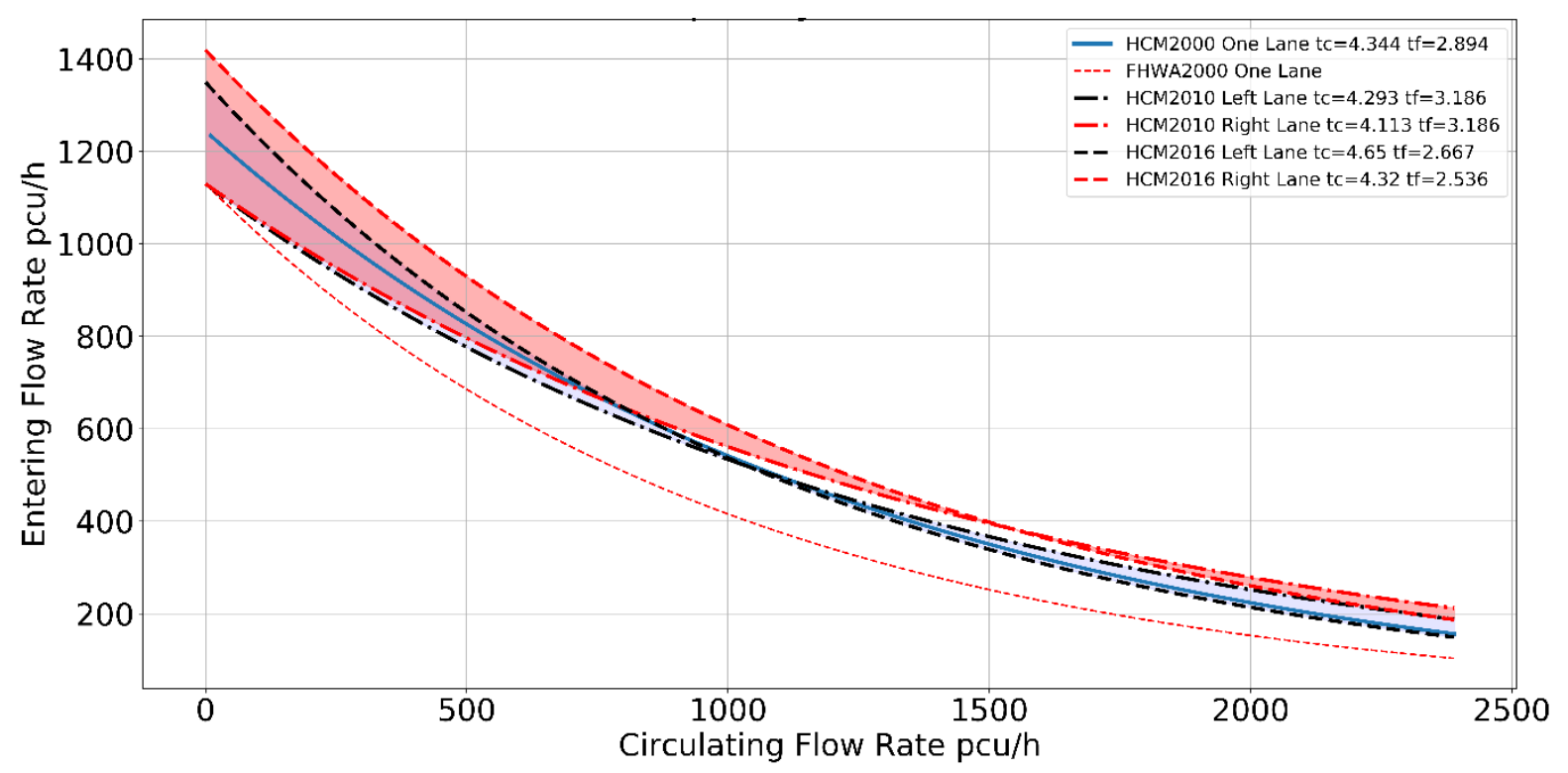

Fig. (9). Roundabout entering capacity versus circulation flow.

The capacity of each roundabout entry is then determined as a function of the conflicting circulating flow using equation (8). The equation includes an intercept term, A, and a slope parameter B. HCM2010 and HCM6 use the same general model except for A and B values (Table 2).

$$
C=A e^{-B v_{c}}
$$

A and B are calculated by critical gap and follow-up time values for corresponding lanes.

$$
\begin{gathered}
A=3600 / t_{f} \\
B=\frac{t_{c}-\left(t_{f} / 2\right)}{3600}
\end{gathered}
$$

To estimate circulating and exiting flow rates at various roundabout approaches, turning movement flow rates (left, trough, right) are used. For multilane roundabouts, the total approach volume needs to be distributed across two lanes. This is a function of the lane assignment (striping of roundabout entry), and the relative turning movement flow rates. The HCM distinguishes five cases, summarized in Table 3 . The volumes are for each respective approach.

For approaches with multiple left or right-turn lanes, additional guidance for estimating the percentage of traffic in the left lane (\% LL) and right lane (\% RL) is found in the HCM

\begin{tabular}{|c|c|c|c|c|c|}
\hline- & \multicolumn{2}{|c|}{$\begin{array}{l}\text { One-lane } \\
\text { entry roundabouts }\end{array}$} & \multicolumn{3}{|c|}{$\begin{array}{l}\text { Two-lane } \\
\text { entry roundabouts }\end{array}$} \\
\hline Lane Number & $1 \times 1$ & $1 \times 2$ & $2 \times 1$ & $\begin{array}{l}2 \times 2 \\
\text { (right) }\end{array}$ & $\begin{array}{l}2 \times 2 \\
\text { (left) }\end{array}$ \\
\hline Entering & 1 & 1 & 2 & 2 & 2 \\
\hline Circulating & 1 & 2 & 1 & 2 & 2 \\
\hline \multicolumn{6}{|c|}{ HCM2010 } \\
\hline $\mathrm{A}$ & 1130 & 1130 & 1130 & 1130 & 1130 \\
\hline B & -0.0001 & -0.0007 & -0.0001 & -0.0007 & -0.00075 \\
\hline \multicolumn{6}{|c|}{ HCM6 } \\
\hline $\mathrm{A}$ & 1380 & 1420 & 1420 & 1420 & 1350 \\
\hline $\mathrm{B}$ & -0.00102 & -0.00085 & -0.00091 & -0.00085 & -0.00092 \\
\hline
\end{tabular}
or can be adopted based on the analyst's judgment [31].

Table 2. A and B parameters [42]. 
Table 3. Lane utilization for multilane roundabouts [31].

\begin{tabular}{|c|c|c|c|}
\hline Case & Assumed lane assignment & center lane & Right lane \\
\hline 1 & $\mathrm{~L}, \mathrm{TR}$ & $\mathrm{vu}_{\mathrm{T}}+\mathrm{v}_{\mathrm{L}}$ \\
\hline 2 & $\mathrm{LT}, \mathrm{R}$ & $\mathrm{vu}+\mathrm{v}_{\mathrm{T}}+\mathrm{v}_{\mathrm{L}}$ & $\mathrm{v}_{\mathrm{R}}$ \\
\hline 3 & $\mathrm{LT}, \mathrm{TR}$ & $(\% \mathrm{LL}) v_{e}$ & $(\% \mathrm{RL}) v_{e}$ \\
\hline 4 & $\mathrm{~L}, \mathrm{LTR}$ & $(\% \mathrm{LL}) v_{e}$ & $(\% \mathrm{RL}) v_{e}$ \\
\hline 5 & $\mathrm{LTR}, \mathrm{R}$ & $(\% \mathrm{LL}) v_{e}$ & $(\% \mathrm{RL}) v_{e}$ \\
\hline
\end{tabular}

Entering lane delay is calculated from the following equation,

$$
\begin{aligned}
d=\frac{3600}{c}+900 T[ & x-1+\sqrt{\left.(x-1)^{2}+\frac{\left(\frac{3600}{c}\right) x}{450 T}\right]} \\
+ & 5 \times \min [x, 1]
\end{aligned}
$$

Where $\mathrm{d}$ is the average lane control delay per vehicle ( $\mathrm{s} /$ vehicle), $\mathrm{T}$ is the time period (h), $\mathrm{x}$ is the volume to capacity ratio for the corresponding lane, $\mathrm{c}$ is the capacity of the corresponding lane (veh/h). The volume-to-capacity ratio is the key input in the equation (11) to estimate the average control delay.

The control delay (dapproach) for an approach is calculated by computing a weighted average of the delay for each lane (dLL, dRL, dbypass) on the approach, weighted by the volume in each lane (vLL,vRL,vbypass) [43].

$$
d_{\text {approach }}=\frac{d_{L L} v_{L L}+d_{R L} v_{R L}+d_{\text {bypass }} v_{\text {bypass }}}{v_{L L}+v_{R L}+v_{\text {bypass }}}
$$

Similarly, the overall roundabout control delay can be calculated as weighted average of the approach delays as shown in Eq. (13).

$$
d_{\text {intersection }}=\frac{\sum d_{i} v_{i}}{\sum v_{i}}
$$

Where, $d_{\text {intersection, }} d_{i}$ and $v_{i}$ are control delay for the entire roundabout (s/veh), control delay for approach ( $/ \mathrm{veh}$ ) and flow rate $(\mathrm{veh} / \mathrm{h})$, respectively.

The LOS values for the approach or intersection corresponding to the delay were determined using the thresholds given in Table 4 .

Following equation is to calculate the 95th percentile queue;

$$
Q_{95}=900 T\left[x-1+\sqrt{\left(1-\frac{\square}{150 T}\right]\left(\frac{c}{3600}\right)}\right.
$$

where, $Q_{95}$ is the 95th percentile queue (veh), $x$ is the volume-to-capacity ratio of the subject lane, $\mathrm{c}$ is the capacity of the subject lane (veh/h), and $\mathrm{T}$ is the period (h).

SIDRA, a micro-analytical software, can conduct the laneby-lane analysis of different intersection types. SIDRA utilizes an iterative approximation method to estimate intersection capacity, total delay, queue lengths and emission levels [44]. The word SIDRA stands for Signalized and Unsignalized Intersection Design and Research Aid. Further development, distribution, and support of SIDRA were undertaken, including workshops and training courses. The SIDRA software program was first developed by Dr. Rahmi Akcelik in 1975-1979. SIDRA 2 based on ARRB Research Report ARR 123 was developed and first released as the main-frame computer program in 1984. Then the program appeared many times in different versions. The SIDRA Intersection program is recognized by Austroads in Australia and New Zealand, in the United States by major sources such as HCM, TRB / FHWA Roundabout Guide. INTERSECTION provides various facilities for calibration of its traffic models for local conditions. The US HCM software setups (Customary and Metric units) of SIDRA INTERSECTION are based on the calibration of model parameters against the Highway Capacity Manual $[45,46]$.

Table 4. Delay interval for LOS [31].

\begin{tabular}{|c|c|}
\hline LOS & Control delay (s/veh) \\
\hline A & $<=10$ \\
\hline B & $>10-15$ \\
\hline C & $>15-25$ \\
\hline D & $>25-35$ \\
\hline E & $>33-50$ \\
\hline F & $>50$ or $\mathrm{v} / / \mathrm{c} \mathrm{ratio}>1.0$ \\
\hline
\end{tabular}

\section{MODELLING EXISTING AND PROPOSED INTERSECTION IN SIDRA}

To model the Sabanc1 Dormitory Intersection in the SIDRA Intersection program, the following sequence has been followed:

- Introduction of intersection geometry to the computer program

- Obtaining information such as the number of crossings, number of lanes, current direction, the numbering of current directions.

- Entering the traffic data into the program

- For each flow, traffic flow rates, PHF, approaching, and intersection speeds are entered.

- Entering the phase plan and signal durations of the intersection into the program

The values of the current situation are determined as a result of the observations made in the working area. After these 
operations, the saturated flow rate has to be entered. The saturation flow rate is 1900 (vehicle $\cdot \mathrm{hr}^{-1}$ ) $\cdot \operatorname{lane}^{-1}$ recommended by TRB for all lanes.

\section{PERFORMANCE OF THE INTERSECTION FOR CURRENT STATE}

Nested signalised roundabouts can not be modelled directly in the SIDRA, so primary and secondary signals are combined into one signal system by adding a secondary green interval to the primary cycle time. The final phase and signal timing of the intersection are shown in Fig. (10) and Table 5, respectively. Finally, capacity and delay are calculated according to the new phase plan. The actual demand for turning movements is given in Table $\mathbf{6}$.

The roundabout in Fig. (11) is built up to compare the current situation with the roundabout application. While designing the intersection, the number and width of the lanes of the existing intersection were taken into consideration. Other geometric features of the designed round-about are given in Table 7.

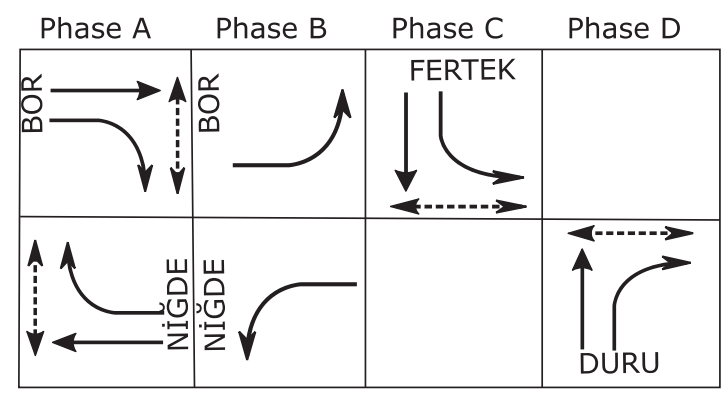

Fig. (10). The current Phase Plan.

Table 5. The current cycle timing and green intervals.

\begin{tabular}{|c|c|c|c|c|}
\hline Phases & A & B & C & D \\
\hline Phase Change Time & 0 & 28 & 53 & 73 \\
\hline Green interval (s) & 24 & 21 & 16 & 13 \\
\hline Total Phase Time & 28 & 25 & 20 & 17 \\
\hline $\begin{array}{c}\text { Percent of phases in the } \\
\text { Cycle Length (\%) }\end{array}$ & 31 & 28 & 22 & 19 \\
\hline
\end{tabular}

Table 6. Volume at approaches.

\begin{tabular}{|c|c|c|c|c|c|}
\hline Legs & Turnings & Vph & Legs & Turnings & Vph \\
\hline Bor & center & 38 & Fertek & center & 169 \\
\hline- & Through & 785 & & Through & 128 \\
\hline- & Right & 340 & & Right & 122 \\
\hline Niğde & center & 210 & Duru & center & 45 \\
\hline- & Through & 650 & & Through & 87 \\
\hline- & Right & 175 & & Right & 62 \\
\hline
\end{tabular}

Table 7. Geometric properties of the proposed roundabout.

\begin{tabular}{|c|c|c|c|c|}
\hline Approximation & Duru & Nĭgde & Fertek & Bor \\
\hline Circulation Lane number & 2 & 2 & 2 & 2 \\
\hline Circulating Width & $10 \mathrm{~m}$ & $10 \mathrm{~m}$ & $10 \mathrm{~m}$ & $10 \mathrm{~m}$ \\
\hline Island Diameter & $30 \mathrm{~m}$ & $30 \mathrm{~m}$ & $30 \mathrm{~m}$ & $30 \mathrm{~m}$ \\
\hline Entry Radius & $20 \mathrm{~m}$ & $20 \mathrm{~m}$ & $20 \mathrm{~m}$ & $20 \mathrm{~m}$ \\
\hline Entry Angle & $30^{\circ}$ & $30^{\circ}$ & $30^{\circ}$ & $30^{\circ}$ \\
\hline
\end{tabular}




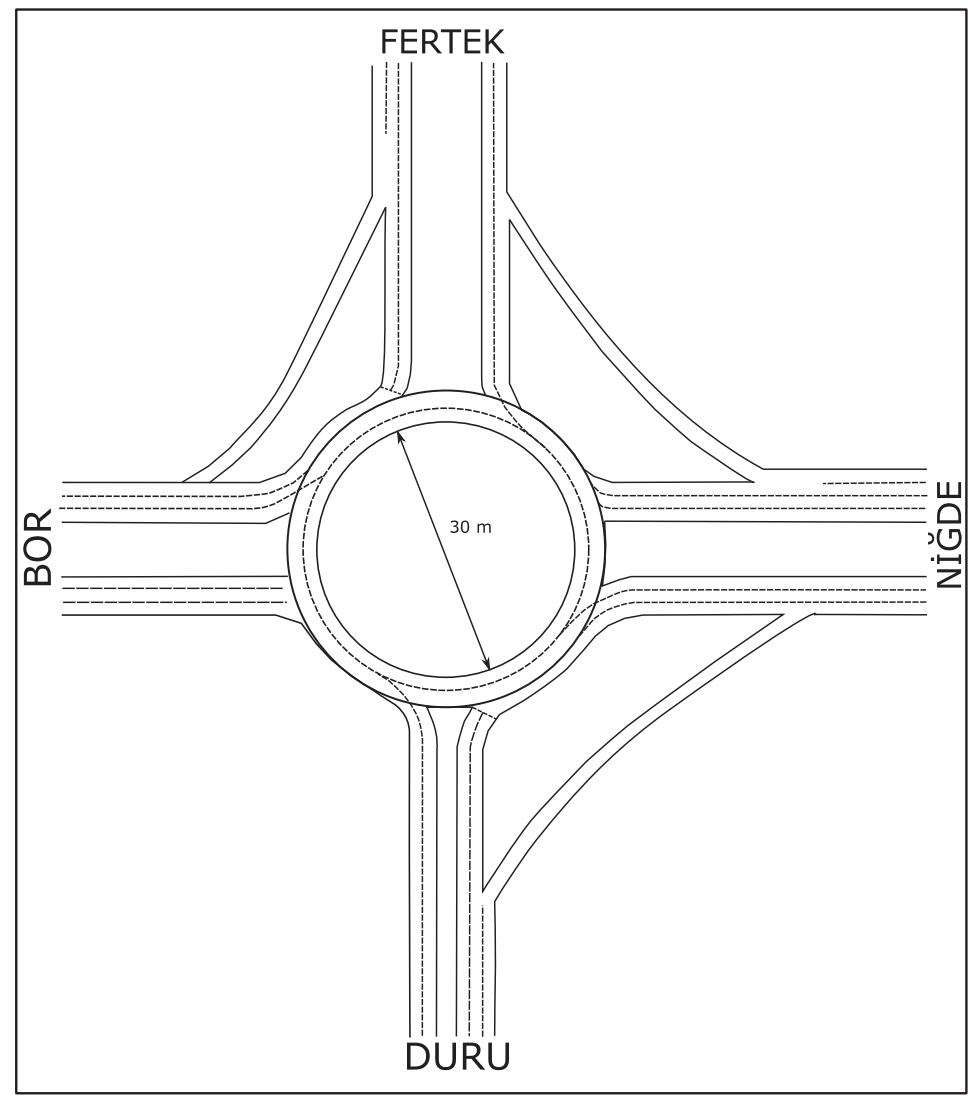

Fig. (11). Roundabout application.

HCM6 method is used to calculate the traffic flow performance for the current situation and roundabout application that are given in Table $\mathbf{8}$.

As shown in Table 8, capacity increased from 3353 to 5627 vehicle per hour $(\% 67.8)$, the average delay decreased from 42.6 to 11.8 seconds ( $\%-72.3)$, and 95 th percentile queue vehicle number dropped from 25.8 to 4.6 vehicle $(\%-82.2)$. The roundabout design produced $11.9 \%$ less hydrocarbon, $9.4 \%$ less carbon dioxide, $9.5 \%$ less fuel consumption. $\mathrm{CO} 2$ and NOX levels decreased by $2 \%$ and $3 \%$, respectively.

From the results of the intersection capacity analysis performed by using SIDRA, it can be seen that the application of roundabout scenario (intersection considered as a modern roundabout) shows higher performance at the intersections than the current state. The proposed roundabout emission outputs is slightly better than the current state.

Table 8. Intersection actual and proposed design output.

\begin{tabular}{|c|c|c|c|}
\hline Performance Measure & The Actual & Roundabout & Differences (\%) \\
\hline- & $\mathrm{A}$ & $\mathrm{C}$ & $(\mathrm{C}-\mathrm{A}) / \mathrm{A}$ \\
\hline Travel Speed (Average) km/h & 31.3 & 44.8 & 43.1 \\
\hline Travel Time (Total) veh-h/h & 82 & 59.4 & -27.6 \\
\hline Degree of Saturation & 0.989 & 0.589 & -40.4 \\
\hline Effective Intersection Capacity veh $/ \mathrm{h}$ & 3353 & 5627 & 67,8 \\
\hline Control Delay (Total) veh-h/h & 39.19 & 10.83 & -72.4 \\
\hline Control Delay (Average) sec & 42.6 & 11.8 & -72.3 \\
\hline Intersection Level of Service (LOS) & LOS D & LOS B & - \\
\hline 95\% Back of Queue - Vehicles (Worst Lane) veh & 25.8 & 4.6 & -82.2 \\
\hline Fuel Consumption (Total) L/h & 288.8 & 261.5 & -9.5 \\
\hline Carbon Dioxide (Total) $\mathrm{kg} / \mathrm{h}$ & 678.6 & 614.5 & -9.4 \\
\hline Hydrocarbons (Total) kg/h & 0.067 & 0.059 & -11.9 \\
\hline Carbon Monoxide (Total) kg/h & 0.821 & 0.78 & -5.0 \\
\hline NOx (Total) kg/h & 0.223 & 0.216 & -3.1 \\
\hline
\end{tabular}




\section{CONCLUSION}

The nested signalized roundabout which is investigated in this study does not reflect the geometric properties of a roundabout. The traffic performance values obtained from the simulation shows that the alternative control application has a higher value than the nested signalized roundabout. Roundabout controlling instead of a nested signal system can be an example of the increase in the performance of traffic flow. This highlights the importance of choosing the appropriate design.

Countries that do not follow roundabout design guidelines such as Turkey, should also take advantage of the existing regulations. Signalized roundabouts design is an expert system because it has no standard design parameters, so the designs of existing signalized roundabouts are mostly based on general road design experience and common sense. From the results, it is suggested that the regulation of traffic and the geometry of intersection should be reviewed. Despite multi-lane types of roundabouts are less safe in comparison with mini and singlelane roundabouts, the signalized roundabouts can overcome the negative effects of it, if designed and controlled properly.

In this study, the fact that the delay values could not be measured in the field is the weakness of the study. The critical gap and follow-up headway in the HCM method directly affect the capacity. Therefore, in the continuation of the study, critical gap and follow-up headway will be observed in a few roundabouts, and deviations from the default values will be investigated.

\section{CONSENT FOR PUBLICATION}

Not applicable.

\section{FUNDING}

None.

\section{CONFLICT OF INTEREST}

The authors declare no conflict of interest, financial or otherwise.

\section{ACKNOWLEDGEMENTS}

Declared none.

\section{REFERENCES}

[1] A. Pratelli, Design of modern roundabouts in urban traffic systems, pp. 83-93. [http://dx.doi.org/10.2495/UT060091]

[2] ODOT, 2012 Highway Design Manual,

[3] W. Brilon, Roundabouts: A State of the Art in Germany., Transportation Research Board, 2014

[4] NCHRP, Roundabouts: An Informational Guide 'Second Edition,", Transportation Research Board, 2010.

[5] H. Pilko, Roundabout design guidelines: Case study of Croatia, 2017, pp. 9-15. [http://dx.doi.org/10.1201/9781315281896-2]

[6] Z. Çakıcı, SInyalize Dönel Kavşakların Tasarım Esaslarının Araștırılması., Pamukkale University, 2014.

[7] SWEROAD, Karayolu Tasarımı Raporu, Ek 4 Şehir Geçişleri ile Illgili Olarak Önerilen Tasarım Esasları, 2000.

[8] FHWA, Roundabouts: An Informational Guide., Virginia, 2000.

[9] L.a. Hoel, N.J. Garber, and A.W. Sadek, Transportation Infrastructure Engineering: A multimodal integration., SI Edition, 2010.
[10] CDDED, Neighborhood traffic calming guidelines adopted by the city council of arroyo grande community development department., Arroyo Grande, 2016.

[11] T. Tollazzi, Alternative Types of Roundabouts at Development Phases, 2015, pp. 157-169.

[http://dx.doi.org/10.1007/978-3-319-09084-9_5]

[12] T. Tollazzi, Alternative Types of Roundabouts: An Informational Guide, 2014.

[13] B. Baronowski, History of the Modern Roundabout, 2011. www.roundaboutsusa.com/history.html

[14] USDOT, Report FHWA-SA-10-006: Technical Summary Roundabouts, 2006

[15] R. Azimi, G. Bhatia, R. Rajkumar, and P. Mudalige, "V2Vintersection management at roundabouts", SAE Int. J. Passeng. Cars Mech. Syst., 2013.

[http://dx.doi.org/10.4271/2013-01-0722]

[16] WSDOT, What is a roundabout? | WSDOT, 2019. https://www. wsdot.wa.gov/Safety/roundabouts/BasicFacts.htm

[17] K. H. Voigt, and B. McCombs, Transportation's role in sustainability, vol. 80. 2010, pp. 40-42.

[18] M. Valdez, R.L. Cheu, and C. Duran, "Operations of modern roundabout with unbalanced approach volumes", Transp. Res. Rec., vol. 2265 , no. 1 , pp. 234-243, 2011.

[http://dx.doi.org/10.3141/2265-26]

[19] VHB, Norwalk Transportation Management Plan DOT01020336PE, 2019.https://portal.ct.gov/DOT/PP Bureau/Transportation-Studies-Sha re-this-pages-direct-link-with-a-friend-or-coworkerwwwctgovdotstudies/Norwalk-Transportation-Management-PlanDOT01020336PE

[20] J. Dahl, and C. Lee, "Empirical estimation of capacity for roundabouts using adjusted gap-acceptance parameters for trucks", Transp. Res. Rec., no. 2312, pp. 34-45, 2012.

[http://dx.doi.org/10.3141/2312-04]

[21] E. Adac-leitfaden, and R. Stock, Der Kreisverkehr., 2005, p. 98 S.

[22] W. Brilon, "Roundabouts: A State of the Art in Germany", proceedings of the National Roundabout Conference, 2005

[23] WDOT, Facilities Development Manual., Wisconsin, 1980.

[24] CDOT, Roadway Design Guide., Colorado, 2018.

[25] H. Ahmed, Multi-Objective optimization of single-lane roundabout geometric design : Safety, mobility, and environmental sustainability., Ryerson University: Toronto, Ontario, Canada, 2018.

[26] Royal Haskoning, Roundabouts - Application and design A practical manual, 2009.

[27] A-M. Azhar, and B. Svante, "Signal Control of Roundabouts", Procedia Soc. Behav. Sci., vol. 16, pp. 729-738, 2011. [http://dx.doi.org/10.1016/j.sbspro.2011.04.492]

[28] V. W. Inman, Synthesis of Literature Relevant to Roundabout Signalization to Provide Pedestrian Access Final Report, 2007.

[29] Z. CAKICI and Y. S. MURAT, "Sinyalize Dönel Kavşaklar için Hesap Yöntemi Önerisi ve Performans Analizi", Teknik Dergi, vol. 27, no. 4, pp. 7569-7592, 2016.

[30] S. HATIPOOĞLU and N. E. OĞUZHAN, "“Sehir içi sinyalize kavşakların yeterliliğinin tasarım kriterleri puanlama yöntemi ile belirlenmesi," Balıkesir Üniversitesi Fen Bilim", Enstitüsü Derg., vol. 20 , no. 1 , pp. $1-15,2018$.

[http://dx.doi.org/10.25092/baunfbed.390930]

[31] D. Findley, B. J. Schroeder, and C. M. Cunningham, "Cunningham, and $\mathrm{Jr}$ Brown", Highway Engineering: Planning, Design, and Operations, 2015.

[32] L.R. Kadiyali, Transportation Engineering., $1^{\text {st }}$ ed Khanna Publishing, 2019.

[33] Z. Qu, Y. Duan, H. Hu, and X. Song, "Capacity and delay estimation for roundabouts using conflict theory", ScientificWorldJournal, vol. 2014, 2014.710938

[http://dx.doi.org/10.1155/2014/710938] [PMID: 24982982]

[34] D. Yin, and T.Z. Qiu, "Comparison of macroscopic and microscopic simulation models in modern roundabout analysis", Transp. Res. Rec., vol. 2265 , no. 1, pp. 244-252, 2011. [http://dx.doi.org/10.3141/2265-27]

[35] D. Stanek, Comparing Roundabout Capacity Methods, or How the Selection of Analysis Method Can Affect the Design, 2012.

[36] W. Cheng, X. Zhu, and X. Song, "Research on capacity model for large signalized roundabouts", Procedia Eng., vol. 137, pp. 352-361, 2016.

[http://dx.doi.org/10.1016/j.proeng.2016.01.269]

[37] J.C. Tanner, "A theoretical analysis of delays at an uncontrolled intersection", Biometrika, vol. 49, no. 1/2, pp. 163-170, 1962. 
[http://dx.doi.org/10.2307/2333477]

[38] O. Hagring, "A further generalization of Tanner's formula", Transp. Res., Part B: Methodol., vol. 32, pp. 423-429, 1998. [http://dx.doi.org/10.1016/S0191-2615(98)00010-1]

[39] O. Hagring, N. Rouphail, and H. Sørensen, "Comparison of capacity models for two-lane roundabouts", Transp. Res. Rec., no. 1852, pp. 114-123, 2003.

[http://dx.doi.org/10.3141/1852-15]

[40] A. Gazzarri, "Gap acceptance parameters for HCM 2010 roundabout capacity model applications in italy", Civ. Eng. Fac. Publ., vol. 1, 2013.

[http://dx.doi.org/10.2495/978-1-84564-764-3/001]

[41] HCM 2010: Highway Capacity Manual., $5^{\text {th }}$ ed Transportation Research Board, c: Washington, D.C., 2010.
[42] J. Chen Rongsheng, "Hourdos, "Evaluation of the roundabout capacity model in HCM6 Edition and HCM 2010 on a multilane roundabout", Transp. Res. Rec., 2018.

[http://dx.doi.org/10.1177/0361198118794287]

[43] TRB, A Guide for Multimodal Mobility Analysis.Highway Capacity Manual., 6th ed Transportation Research Board: Washington, D.C, 2016.

[44] P. Ranjitkar, A. Shahin, and F. Shirwali, "Evaluating operational performance of intersections using SIDRA", Open Transp. J., vol. 8, pp. 50-61, 2014.

[http://dx.doi.org/10.2174/1874447801408010050] $\begin{array}{ll}\text { [45] SIDRA } & \text { 2019.http://www.sidrasolutions.com/Company/Projects }\end{array}$

Solutions,

[46] R. Akçelik, An Assessment of the Highway Capacity., Manual Edition 6 Roundabout Capacity Model, 2017.

\section{2020 Hatice Göçmen Demir and Yusuf Kağan Demir.}

This is an open access article distributed under the terms of the Creative Commons Attribution 4.0 International Public License (CC-BY 4.0), a copy of which is available at: (https://creativecommons.org/licenses/by/4.0/legalcode). This license permits unrestricted use, distribution, and reproduction in any medium, provided the original author and source are credited. 